\title{
Possíveis confluências filosóficas e pedagógicas entre a educação ambiental crítica e a Pedagogia Histórico-Crítica
}

\author{
Possible philosophical and pedagogical influences between \\ critical environmental education and Historical-Critical Pedagogy
}

\author{
Magno da Conceição Peneluc ${ }^{1}$. Bárbara Carine Soares Pinheiro ${ }^{2}$. \\ Edilson Fortuna de Moradillo ${ }^{2}$
}

\begin{abstract}
Resumo: O presente artigo propõe um debate sobre as relações filosóficas - ontológicas e epistemológicas - e político-pedagógicas entre a Educação Ambiental, em sua vertente crítico-marxiana, e a Pedagogia Histórico-Crítica. Postula-se que, ao se embasar no materialismo histórico-dialético, a Educação Ambiental constitui-se em um aparato teórico e metodológico valoroso, especialmente por potencialmente desenvolver um ato pedagógico emancipador, transformador e crítico, além de apresentar relevante potencial heurístico no desvelamento dos aspectos ideológicos e político-ecológicos da crise socioambiental. A educação ambiental crítica alinhada à Pedagogia Histórico-Crítica poderia, portanto, desenvolver uma práxis desveladora de conflitos socioambientais, no contexto do ensino e da aprendizagem escolar. Busca-se argumentar sobre a relevância da Pedagogia Histórico-Crítica na proposição de uma práxis de ensino que utilize a mediação didática como via de ajuste de conhecimentos científicos à realidade da sala de aula e à realidade sociocultural do estudante, em especial no tocante à relação sociedade e ambiente.
\end{abstract}

Palavras-chave: Educação ambiental. Materialismo histórico-dialético. Pedagogia Histórico-Crítica.

\begin{abstract}
This article proposes a debate on the philosophical - ontological and epistemological - and political-pedagogical relations between Environmental Education, in its critical-Marxian aspect, and the Historical-Critical Pedagogy. It is postulated that, based on historical-dialectical materialism, Environmental Education constitutes a valuable theoretical and methodological apparatus, especially for potentially developing an emancipatory, transformative and critical pedagogical act, besides presenting relevant heuristic potential in the elucidation of the ideological and political-ecological aspects of the socio-environmental crisis. Critical Environmental Education aligned with Historical-Critical Pedagogy could, therefore, be able to develop a praxis that reveals socio-environmental conflicts, in the context of teaching and school learning. The paper tries to argue for the relevance of the Historical-critical Pedagogy in the proposal of a teaching praxis that uses didactic mediation as a way of adjusting scientific knowledge to the reality of the classroom and to the socio-cultural reality of the student, especially in relation to the interface of society and environment.
\end{abstract}

Keywords: Environmental education. Historical-dialectical materialism. Historical-Critical Pedagogy.

\footnotetext{
${ }^{1}$ Universidade Federal da Bahia (UFBA), Instituto de Física, Programa de Pós-graduação em Ensino, Filosofia e História das Ciências, Salvador, BA, Brasil. E-mail: <bio.magno@gmail.com>.

${ }^{2} \mathrm{UFBA}$, Instituto de Química, Salvador, BA, Brasil.
} 


\section{Introdução}

A Educação Ambiental vem sendo cada vez mais discutida, especialmente por aqueles que a consideram um arcabouço promissor e estratégico à Gestão Ambiental e à formação de sujeitos críticos e atuantes em seus respectivos socioambientes e na educação formal. Dentre os diversos aspectos levantados sobre o potencial da Educação Ambiental, encontra-se a discussão da necessária aproximação desta às teorias pedagógicas, em especial às teorias críticas.

Em sua vertente crítico-marxiana, a Educação Ambiental Crítica (EAC) assume como pressuposto ontológico a constituição histórica do ser social, que por meio da transformação da natureza, viabilizada pelo trabalho, determina o modo como satisfazemos nossas necessidades e o nosso próprio modo de existir como indivíduos em sociedade (LOUREIRO; TOZONI-REIS, 2016). No tocante à EAC, o Materialismo Histórico-dialético (MHD), além de ser sua fundamentação filosófica e política é também seu método de pesquisa sobre as relações sociedade/natureza. Desta forma, ao dialetizar sobre a relação entre a produção, a circulação, a distribuição e o consumo, o MHD proporciona uma visão de totalidade dialética que explicita a interdependência global entre os setores econômicos, políticos, cultural e natural. Loureiro (2015), partindo deste caráter do MHD, esclarece que há diversos motivos do porquê este deve ser assumido centralmente como método da EAC. Enquanto método é fundamental na compreensão sobre como os seres humanos realizam suas relações com a natureza, tanto no que se refere às formas de apropriação, identidade e pertencimento; historicizando-os, no âmbito das relações sociais e modos de produção. A categoria da concreticidade do MHD proporciona uma interpretação mais realista dos processos de apropriação da natureza em sua relação com a produção material e cultural, ou, dito de uma outra forma, das objetivações que a humanidade realiza sob o modo de produção capitalista. Assim, sem fragmentar a análise, impede conclusões maniqueístas e proporciona uma visão dialética de totalidade enquanto unidade composta de múltiplas objetivações relacionadas dialeticamente, ou seja, concebendo a sociedade como um complexo de complexos (LUKÁCS, 2010).

A interdependência entre a sociedade e a natureza, está implícita na categoria de história: "a natureza, devindo na história por meio do ato da produção da sociedade, é a própria natureza humana, que se constitui na dinâmica da natureza, pressuposto da atividade humana" (LUKÁCS, 2010, p. 58). O que caracteriza e determina a especificidade da atividade humana é a transformação da atividade natural em uma atividade posta, ou seja, é a configuração objetiva de um fim previamente estabelecido - o pôr teleológico, prévia ideação objetivada pelo trabalho. Trabalho é a unidade entre o pôr efetivo de uma dada objetividade e a atividade ideal prévia diretamente regida e mediada por uma finalidade específica (LUKÁCS, 2010). Mais especificamente:

Os três tipos de $\operatorname{ser}^{3}$ existem simultaneamente, entrelaçados entre si, e exercem também efeitos muitas vezes simultâneos sobre o ser do homem, sobre sua práxis. É preciso ter sempre em mente que uma fundamentação ontológica correta de nossa imagem de mundo pressupõe as duas coisas,

\footnotetext{
${ }^{3}$ Lukács (2010) se refere aos componentes categoriais centrais da ontologia humana: a conexão e a diferenciação dos três grandes tipos de ser (os seres das naturezas inorgânica, orgânica e o ser social).
} 
tanto o conhecimento da propriedade específica de cada modo de ser como o de suas interações, inter-relações etc. com os outros. Nas duas direções, o desconhecimento da verdadeira relação (unidade na diversidade, por meio dela a separação e a oposição nas interações homogêneas etc.) pode conduzir às maiores distorções do conhecimento daquilo que é o ser. $\mathrm{O}$ ser humano pertence ao mesmo tempo (e de maneira difícil de separar no pensamento) à natureza e à sociedade. (LUKÁCS, 2010, p. 37).

Esta noção ontolológica rebate nas premissas constitutivas da proposta politico-pedagógica da PHC e também da EAC. A educação formal ou escolar vem sendo foco de atenção de pesquisadores educacionais da PHC. Embasada na tradição materialista histórico-dialética, a PHC propõe uma educação atuante, historicizada e crítica (no sentido de análise radical dos fenômenos sociais e culturais no seio da sociedade dividida em classes desiguais impressas sob um modo de produção desumanizante) que supere o capital com sua formação de excedentes para a troca, geração de resíduos, consumo excessivo, individualismo e alienação do trabalho. A EAC, por sua vez, no que se refere ao contexto escolar, está buscando promover a compreensão das contradições do capital, em especial a contradição entre apropriação privada dos meios de produção e a alienação do trabalho, a contradição entre capital e natureza, além da superação da fragmentação do saber pedagógico; reconhecendo nos estudantes seres sociais concretos, síntese de relações sociais imersas numa realidade social conflitiva (KUENZER, 2005; LOUREIRO et al., 2009; SAVIANI; DUARTE, 2012).

Academicamente, a EAC vem também se fundamentando no MHD, o qual vem construindo sua identidade epistemológica. Seu sujeito/objeto de análise, a humanidade e sua história fundada pelo trabalho e seus diversos meios de modificar a natureza, especialmente no tocante aos aspectos da crise socioambiental, considerada aqui como uma crise resultante das urgências demandadas por um modo de produção baseado na exploração/precarização do trabalho e na necessária taxa crescente de produção. A educação deve ser considerada como um complexo social estratégico que mantém uma relação dialética com outros complexos da sociedade (Estado, organizações do setor civil, setor produtivo, dentre outros) e como meio de humanização; não uma vítima passiva do sistema e seu modo de produção, como nas teorias crítico-reprodutivistas (SAVIANI, 2009). Considerando este papel da educação, deve-se refletir sobre a função da educação escolar na formação do indivíduo, ser social complexo de múltiplas objetivações. À educação escolar, portanto, figuraria um papel formativo e mediatizador das relações indivíduo-sociedade (DUARTE, 2007). A EAC, seguindo o mote da PHC, pretende desenvolver condições para a apropriação pelos indivíduos dos instrumentos culturais produzidos socialmente e acumulados historicamente pelos seres humanos; o que tornaria possível a geração de conhecimentos potencialmente emancipatórios (MAIA, 2015). Esta atribuição assumida pela EAC possui clara influência da definição clássica de educação, assim descrita por Saviani (2013, p. 6) "o trabalho educativo é o ato de produzir, direta e intencionalmente, em cada indivíduo singular, a humanidade que é produzida historicamente e coletivamente pelo conjunto dos homens".

Considerando este propósito da educação escolar, emerge a necessidade de realizar um debate sobre os aspectos político-pedagógico e epistemológico da EAC. Postula-se que, ao se embasar no materialismo histórico-dialético, a Educação Ambiental constitui um aparato teórico 
e metodológico valoroso, especialmente por se debruçar sobre a relação sociedade/natureza e ao desvelar aspectos ideológicos e político-ecológicos da crise socioambiental. O educador ambiental fundamentado na PHC poderia concretizar um ato pedagógico crítico e emancipatório, didatizando os conteúdos socioambientais, no contexto do ensino e da aprendizagem escolar.

Buscou-se, em decorrência, argumentar sobre a atribuição assumida pela PHC na proposição de práxis de ensino utilizando a mediação didática como via de ajuste de conhecimentos sistematizados (científicos, filosóficos e artísticos) com foco na socialização dos saberes historicamente acumulados pela humanidade, mediatizados à realidade da sala de aula (SALA, 2010; SAVIANI, 2013). A ênfase tipicamente recai sobre a ciência, enquanto conhecimento sistematizado pela humanidade, relacionado principalmente à desfetichização/desmascaramento da aparência falseadora da realidade (DUARTE, 2016). O que se pretende é avançar da quotidianidade plasmada pelos conceitos espontâneos, até os conceitos científicos, os quais estabelecem com os fenômenos da realidade uma relação objetiva; o que não quer dizer que a arte (e a Filosofia) não cumpra uma função desfetichizadora ou de desmacaramento de aparências (DUARTE, 2016; DUARTE et al., 2013).

\section{A pedagogia crítica, a educação ambiental crítica e o materialismo histórico-dialético}

Marx compreende de forma radical o ser humano: pelo trabalho, ao transformar a natureza, a humanidade cria novas possibilidades e necessidades objetivas (LESSA; TONET, 2011). A ontologia marxiana centraliza o trabalho como o principal agente mediador da relação ser humano-natureza. Já que "[...] o trabalho é o único meio pelo qual o homem aumenta o valor dos produtos da natureza, enquanto o trabalho é sua propriedade ativa" (MARX, 2008, p. 29). Enquanto propriedade ativa, o trabalho é o meio pelo qual a humanidade se objetiva na história, produzindo sua existência. Em decorrência das formas de produção da sua própria existência, o ser humano, considerando suas organizações sociais, constitui objetivamente seu corpo e suas imagens ideológicas (representacionais) da natureza. Ou seja, o trabalho é sua atividade vital, o qual como vida produtiva é o único meio que satisfaz a sua existência física. "A vida como meio de vida" (MARX, 2008, p. 116).

O trabalho implica, pois, um movimento indissociável em dois planos: num plano subjetivo (pois a prefiguração se processa no âmbito do sujeito) e num plano objetivo (que resulta na transformação material da natureza); assim, a realização do trabalho constitui uma objetivação do sujeito que o efetua. (NETTO; BRAZ, 2009, p. 32).

Ao admitir o ser humano como cultural e natural, deve-se compreender que ao mesmo tempo que históricos, somos seres naturais. Ou seja, "esse comportamento do homem social consigo mesmo como ser natural é um processo histórico objetivo e até irreversível". (LUKÁCS, 2010, p. 38). De acordo com a dialética marxiana, a essência humana e a essência da natureza formam uma unidade histórica e natural, não cabendo interpretações dicotomizadas entre natureza e cultura (LOUREIRO, 2014). Como Marx (2008) já havia esclarecido, a vida 
genérica (social e histórica) consiste da interconexão que o homem estabelece na/com a natureza orgânica e inorgânica, sendo esta o seu corpo físico-natural, seu meio de vida e sua vida mental (cultura, história). Portanto, a natureza interconectada com ela mesma. A mediação metabólica que o ser humano realiza com a natureza, práxis mediada pelo trabalho, redunda num assunção ontológica dialética e histórica que abre perspectiva para a transformação histórica e natural.

A categoria da mediação, central à práxis laborativa, significa que “o processo pelo qual o homem, destacando-se da natureza entra em contradição com ela necessitando negá-la para afirmar sua humanidade. Dessa forma, um ser natural, o homem, torna-se obrigado, para existir, a produzir sua própria vida agindo sobre a natureza e transformando-a" (SAVIANI, 2015, p. 33). Isto que acaba por reafirmar que a sociedade só pode existir em permanente intercâmbio com a natureza, concebendo o seu desenvolvimento de forma histórica e contraditória (DUARTE, 2012; LOUREIRO, 2014). A centralidade do trabalho enquanto categoria mediadora entre o ser e a natureza é premissa ontológica basal para ambas as escolas aqui analisadas. Em termos pedagógicos, a práxis laborativa do professor deve viabilizar a mediação dos conteúdos com a realidade. Somente por meio da educação o ser humano pode negar positivamente a realidade dada e se construir humano. Por isso a mediação é critério ontológico e educativo, pois sua formação e produção se confundem no ato pedagógico. Assim:

Se a existência humana não é uma dádiva natural, mas tem que ser produzida pelos próprios homens, sendo, pois, um produto do trabalho, isto significa que o homem não nasce homem. Ele se forma homem. Ele não nasce sabendo produzir-se como homem. Ele necessita aprender a ser homem, precisa aprender a produzir sua própria existência. Portanto, a produção do homem é, ao mesmo tempo, a formação do homem, isto é, um processo educativo. A origem da educação coincide, então, com a própria origem do homem. A produção da existência implica o desenvolvimento de formas e conteúdos cuja validade é estabelecida pela experiência, o que configura um verdadeiro processo de aprendizagem. Assim, enquanto os elementos não validados pela experiência são afastados, aqueles cuja eficácia a experiência corrobora necessitam ser preservados e transmitidos às novas gerações no interesse da continuidade da espécie. O homem é, pois, um produto da educação [...]. A categoria de mediação é central na pedagogia históricocrítica a tal ponto que, para essa teoria pedagógica, a educação é entendida como uma atividade mediadora no interior da prática social global. Como tal, o ponto de partida e o ponto de chegada da prática educativa é a prática social. (SAVIANI, 2015, p. 34).

Enquanto vertente da educação, a EAC tem como objeto a relação ser humano-natureza, que possui nas categorias de história e contradição premissas essenciais. A problematização desta complexa relação dialética, considerando todas suas contradições, motores de seu movimento histórico, nos conduz, por fim, à tarefa da EAC enquanto processo político-pedagógico de apropriação crítica e reflexiva de conhecimento, atitudes, valores e comportamentos voltados à transformação social, à transformação das relações dos seres humanos entre si e deles com o ambiente no sentido histórico (TOZONI-REIS, 2007). 
A Educação Ambiental, em sua vertente crítica, tem como método e fundamentação teórico-filosófica o materialismo histórico-dialético. É caracterizada pela categoria da dialética, pela crítica da razão instrumental (racionalista, não-crítica) e pela crítica aos processos de legitimação das ideologias capitalistas. Ao elucidar as relações entre o ser humano e a natureza na perspectiva do materialismo histórico, as múltiplas dimensões humanas (biológica, psicológica, cultural e política) e suas variadas formas de interação, necessitam de uma análise histórica cujo método abarque a complexidade da natureza e do ser humano que se impõem. Apoiada na dialética marxiana, a forma de apreender ou mesmo de recortar o real passa a ser historicizada, concreta, fundada no seio de transformações sociais e naturais. A EAC, enquanto práxis política, visa a transformação social.

A especificidade da EAC, como decorrente da assunção epistemológica do materialismo histórico-dialético, fica assim bem explícita:

O que procuramos expressar até aqui é o contexto de crise socioambiental em que as práticas educativas se realizam ao considerar o compromisso social de que se revestem, no sentido de problematizar as relações que temos estabelecido historicamente com a natureza. Como temos construído conhecimentos sobre a realidade, que leituras de mundo temos feito e em que medida elas se constituem em leituras crítico-reprodutoras ou se convertem em crítico-transformadoras? (TREIN, 2012, p. 308).

A EAC tem como atributo o processo histórico de afastamento do ser humano perante a Natureza, enfatizando:

[...] a função moral de socialização humana ampliada à Natureza, percebe o ser humano como uma continuidade da Natureza que num certo momento histórico teve sua trajetória desviada, sendo que a Cultura representaria a Natureza consciente de si, justificando, portanto, que o sistema educativo pressionado pela crise ambiental buscasse a reaproximação do humano perante a Natureza, através da correção do rumo civilizatório baseado na extensão do processo de socialização ampliado à Natureza. Nesse sentido, uma das questões centrais do debate no campo da educação ambiental gira em torno da ampliação da esfera da ética, agora também ecológica, através da promoção de uma mudança cultural (LAYRARGUES, 2006, p. 2).

Para além de criticar e negar o real histórico existente, busca-se propor outras direções, outras visões de mundo, outras dimensões de vida, almejando a formação do ser humano integral (TREIN, 2012). Concebida como processo de humanização, a EAC tematiza as relações dialéticas sociedade/natureza, enfatizando as condições de existência humana no mundo, buscando a formação ominilateral (integral) de um ser humano conscientemente transformador do meio e com vistas à construção de um novo paradigma de sociabilidade que, em seu projeto societário, se baseie nos limites e capacidades de resiliência da natureza. A EAC possui como atributo central a negação de qualquer concepção que dissocie a natureza da sociedade, o que redundaria na naturalização dos processos históricos de produção de mais-valor, de alienação, 
de opressão e de hegemonia. O que resulta numa postura emancipatória e transformadora. $\mathrm{O}$ termo "Crítica" se refere à negação e à superação dialética das relações alienadas típicas do capitalismo, relações que são orgânicas ao metabolismo social do capital, em sua totalidade (LOUREIRO, 2015).

A meta de superação positiva da sociedade capitalista está também explícita em Saviani e Duarte (2012), que afirmam que a educação crítica deve essencialmente tematizar as repercussões históricas do trabalho alienado pela sua transformação em autoatividade - meio de humanização, ela mesma um processo de desenvolvimento e realização do ser humano. Conclusivamente, esta superação práxica humanizadora só seria possível por meio da formação omnilateral, sujeito social formado uma base filosófica revolucionária e contra-hegemônica (BIRAL, 2014; KUENZER, 2005; SAVIANI, 2015; TOZONI-REIS; CAMPOS, 2014).

A dialética materialista histórica marxiana é embasada nos conceitos de totalidade e concreticidade (que serve à compreensão mais completa possível do real histórico); e historicidade e contraditoriedade (que revela o caráter dinâmico do pensamento dialético) (TOZONI-REIS, 2007). "Para a filosofia da práxis, o ser não pode ser separado do pensar, o homem da natureza, a atividade da matéria, o sujeito do objeto; se se faz esta separação, cai-se em uma das muitas formas de religião ou na abstração sem sentido" (GRAMSCI, 1996, p. 70). Bem entendido:

O método, compreendido como instrumento filosófico, social e científico de análise, tem na dialética de Marx seu instrumento lógico de interpretação da realidade educacional de dimensão socioambiental. Nosso ponto de partida, portanto, o método materialista histórico-dialético desenvolvido por Marx um método de interpretação da realidade, visão de mundo e práxis. O caráter material do método diz respeito à organização da sociedade para a produção e a reprodução da vida e o caráter histórico busca compreender como se organizou a sociedade através da história, isto é, procura desvendar, para interpretação da realidade, as formas históricas das relações sociais estabelecidas pela humanidade (LOUREIRO et. al, 2009, p. 86, grifo do autor).

Segundo Tozoni-Reis (2007), a consequência da organização social do trabalho no capitalismo, ou seja, um trabalho imposto, alienado, resulta na alienação das pessoas humanas: delas entre si e delas em relação à natureza. A dialética, a totalidade e a práxis são consideradas aqui como fatores centrais. Ou seja, teoria e prática não estão descoladas. Nem tampouco, perspectivas reducionistas e pragmáticas irão conduzir a uma práxis pedagógica transformadora e crítica (LOUREIRO; VIÉGAS, 2013). Neste sentido, a EAC deve ser adotada enquanto promotora da mudança ambiental por intermédio da mudança social.

Ao elucidar as relações humano/natureza mediante a perspectiva do materialismo histórico, as múltiplas dimensões e suas variadas formas de interação, o real concreto passa agora, necessariamente, por uma análise histórica que depende de um método que abarque a complexidade que se impõe. "O concreto é concreto, porque é a síntese de muitas determinações, isto é, unidade do diverso. [...] as determinações abstratas conduzem à reprodução do concreto por meio do pensamento" (MARX, 2007, p. 256). Tal noção de real concreto - significando um todo dialético e estruturado assume a noção de processo, de movimento epistemológico que procede do todo às partes e das partes ao todo, dos fenômenos à suas essências e vice-versa, 
da totalidade às suas contradições e das contradições à totalidade (KOSIK, 2011) - é central na construção da noção de conhecimento pedagógico (escolar) e na função política da escola no tocante também à PHC.

A EAC, por seu turno, tradicionalmente se utiliza da dialética marxiana como método de análise das realidades socioambientais, o que permite construir conhecimentos que são utilizados em programas educacionais voltados a comunidades e coletivos os quais são sujeitos de conflitos socioambientais, em grande parte dos casos. Isto porque a EAC concebe de forma dialética a totalidade das relações entre sociedade e natureza, indivíduo e sociedade, e de forma não fragmentada busca superar a alienação derivada do capital, interpretando a realidade por meio das categorias de práxis e de totalidade (LOUREIRO; TOZONI-REIS, 2016).

A seguir trataremos de algumas particularidades definidoras PHC que podem ser de grande valia à EAC, particularmente como via de sua inserção no currículo enquanto modalidade nuclear.

\section{Fundamentos filosóficos, pedagógicos e epistemológicos da Pedagogia Histórico-Crítica e sua possível contribuição pedagógica para a educação ambiental crítica}

O que há de mais humano nos seres humanos é a cultura. Para que esta seja construída tem haver intencionalidade, prévia-ideação e objetivação - o que se concretiza por meio do trabalho. Todavia, no que se refere ao trabalho educativo, significa:

\footnotetext{
Dizer, pois, que a educação é um fenômeno próprio dos seres humanos significa afirmar que ela é, ao mesmo tempo, uma exigência de e para o processo de trabalho, bem como é, ela própria, um processo de trabalho. Assim, o processo de produção da existência humana implica, primeiramente, a garantia da sua subsistência material com a consequente produção, em escalas cada vez mais amplas e complexas, de bens materiais; tal processo nós podemos traduzir na rubrica "trabalho material". Entretanto, para produzir materialmente, o homem necessita antecipar em ideias os objetivos da ação, o que significa que ele representa mentalmente os objetivos reais (SAVIANI, 2015, p. 286).
}

Assumindo o trabalho como o meio de humanização, para que se possa compreender a natureza da educação é necessário que se especifique exatamente o que se entende por trabalho. Saviani (2013) estabelece uma distinção entre trabalho material e trabalho não material. No primeiro tipo o produto se separa do produtor, no segundo não se dá esta separação. Sendo assim: "É nessa segunda modalidade de trabalho não material que se situa a educação. Podemos, pois, afirmar que a natureza da educação se esclarece a partir daî" (SAVIANI, 2013, p. 12). Desde esta definição pode-se inferir que a matéria prima da educação é o saber objetivo produzido historicamente, o mundo da cultura, o saber metódico e sistemático (SAVIANI, 2013). Esta noção ontológica de formação humana (do ser social) é decididamente comum a ambas as vertentes educacionais aqui tratadas. 
Compreendida a natureza da educação, parte-se para a sua especificidade, o que se refere ao seu objeto.

Assim, o objeto da educação diz respeito, de um lado, à identificação dos elementos culturais que precisam ser assimilados pelos indivíduos da espécie humana para que eles se formem humanos e, de outro lado e concomitantemente, à descoberta das formas mais adequadas para atingir esse objetivo. (SAVIANI, 2015, p. 287).

Tendo como propósito “a socialização do saber sistematizado” (SAVIANI, 2015, p. 288), o que está explícito aqui é o papel do professor como mediador insubstituível na relação do estudante com este saber sistematizado - a ciência -, por meio de um processo de transmissão-apropriação (pode-se encontrar o termo transmissão-assimilação na literatura, sem nenhum prejuízo epistêmico).

Os diversos adjetivos que neste artigo qualificam o termo Pedagogia podem ser reorganizados em torno de uma práxis de ensino formal propositora de procedimentos de ensino facilmente discerníveis. O trabalho educativo deve estar voltado para a formação do indivíduo, no sentido de maximizar as possibilidades desta formação, objetivando a compreensão crítica com vistas à superação do modo de produção capitalista. Mas como compreender e superar este modo de produção e organização social? (DUARTE, 2007). O conceito de alienação pode ser um bom meio de iniciar este processo compreensivo.

Lessa e Tonet (2011) esclarecem que a ação e seu resultado são sempre projetados na consciência antes de serem construídos na prática. Prévia-ideação e concretização (objetivação) por meio do trabalho são a síntese da essência humana. Porém, os homens podem agir para alterar as consequências dos seus atos sem que isso signifique que possam fazer da realidade exatamente aquilo que almejam. É nesta distância entre intenção e gesto que encontramos a possibilidade de surgir a alienação. Deve-se ressaltar que os processos de alienação, intencionais ou não, prestam papel essencial na reprodução do capital e de suas consequências deletérias ao meio ambiente. Cabe, portanto, à educação o processo dialético de humanização do gênero humano, dentro dos processos sociais de dominação (alienação), dialetizando a relação objetivação-apropriação e a relação ser humano-natureza. (DUARTE, 2007).

A atividade de mediar conhecimentos do socioambientalismo crítico à sala de aula talvez ainda careça de uma noção mais explícita de currículo e de conteúdos escolares. Conjunto de conhecimentos, conteúdos a serem ensinadas, práticas interativas escolares, planejamento de atividades didáticas - o currículo deve ser claramente definido para que os processos interventivos sejam objetivamente direcionados e embasados filosoficamente por um projeto societário sustentado pela categoria de totalidade.

Como uma atividade nuclear, os conteúdos advindos da matriz socioambiental, ao serem transpostos ao universo escolar, devem ter como principal finalidade construir (e promover a apropriação) de conhecimentos para a emancipação e transformação das sociedades desiguais. Não obstante, tornam-se centrais as questões levantadas por TOZONI-REIS et. al. (2013, p. 7) "Como esses conteúdos podem ser definidos e selecionados? Por quem? Para quê? Para quem?"

Como Saviani (2009, p. 50) alerta: “os conteúdos são prioridade porque o domínio da cultura constitui instrumento indispensável para participação política das massas”. Em termos 
de processo-finalidade do ato educativo voltado para construção da existência através da reprodução do conhecimento, este ato deve sempre contemplar a relação entre o estudante e o conhecimento, integrando conteúdo e método, propiciando o domínio intelectual das práticas sociais e produtivas (KUENZER, 2005). Neste processo o professor possui papel central. Papel de conduzir a superação dos estudantes dos conhecimentos sincréticos, fortuitos e heterônomos à compreensão da realidade a partir dos conhecimentos sistematizados já conquistados pela humanidade. Para concretizar este pleito, o professor deve ser formado considerando a natureza da sua própria atividade, o ato de ensinar (MARTINS, 2010). O pleno desenvolvimento humano não se dará sem a transmissão-apropriação de conhecimentos, estes, por sua vez, destituídos da sua forma burguesa, mas objetivando as potencialidades criativas humanas, enquanto totalidade histórica (DUARTE, 2010). Por isso: “A formação profissional deve pautar-se pela organização intencional dos conteúdos desse processo e levar em conta as condições objetivas de sua efetivação.” (MARSIGLIA; MARTINS, 2013, p. 97).

A PHC propõe uma educação radialmente diferente da educação burguesa, portanto, considerar este caráter classista e interessado da educação é essencial à pedagogia socialista. Em decorrência, o trabalho educativo escolar deve consistir na socialização do conhecimento em suas formas mais desenvolvidas. Ao mesmo tempo, reconhecendo que este conhecimento é parte dos meios de produção que são de propriedade do capitalista (SAVIANI; DUARTE, 2012).

A PHC possui como premissas primazes a valorização dos conteúdos (científicos, filosóficos e artísticos), a centralidade do professor no processo de ensino e aprendizagem, o papel social e político da escola e a relação forma-conteúdo-destinatário. Sobre a relação formaconteúdo, podemos compreender que:

[...] a forma de transmitir os conteúdos não deve ser mais importante do que estes em si. Os conteúdos são os objetos do trabalho pedagógico, de modo que a função primaz da escola e do professor é tornar estes conteúdos públicos; de modo a nos apropriarmos deste legado cultural dando continuidade à história da humanidade, sem precisarmos reinventar a nossa cultura a cada nova geração (PINHEIRO, 2016, p. 122).

Por isso, os passos/momentos da PHC (ver no próximo tópico) contemplam também os métodos de mediar os conteúdos na sala de aula. Nela o professor deve pretender a formação de um indivíduo emancipado humanamente, que não sirva só para saber os seus direitos e cumprir os seus deveres, mas que seja crítico o suficiente para romper com eles quando estes forem injustos e aprisionadores. Por isso a apropriação de conteúdos científicos nos possibilita uma reflexão mais profunda da realidade e a produção de uma expressão mais elaborada da cultura popular (PINHEIRO, 2016).

A EAC tem como desafio contemporâneo ser implementada de forma qualificada nas escolas. A inserção de forma nuclear no currículo da escola é fundamental, dentre outros aspectos, para que a EAC se alinhe aos pressupostos político-pedagógicos da PHC. Enquanto atividade nuclear desenvolvida no contexto escolar o currículo é

[...] 'o conjunto de atividades nucleares desenvolvidas pela escola'. Nucleares porque estamos tratando de um processo de apropriação de saberes - que in- 
cluem conhecimentos, ideias, conceitos, valores, símbolos, hábitos, atitudes, habilidades - que instrumentalizam os estudantes para a prática social mais ampla, mas que desse ponto de vista têm que se constituir num processo organizado, intencional, sistematizado. Portanto, currículo não é "tudo", mas um conjunto de atividades organizadas, intencionalmente voltadas para a formação dos alunos (TOZONI-REIS; CAMPOS, 2014, p. 149).

A inserção dos conteúdos da EAC no currículo, como aqui defendemos, deve partir da meta de uma formação humana omnilateral. Por meio da mediação dos conteúdos clássicos (fundamentais e genéricos no sentido de representativos da genericidade humana) e primando pela apropriação/assimilação crítica dos conhecimentos produzidos ao longo da história da humanidade (TOZONI-REIS; CAMPOS, 2014).

A relevância do trabalho dos professores é central à concretização das propostas didáticas da PHC. Tozoni-Reis et al. (2013) esclarecem que as atividade pedagógicas executadas pelo professor exige capacidade de apropriação crítica dos conteúdos científicos e dos saberes elaborados pela cultura com vistas a mediá-los por meio de métodos de ensino mais adequados. Trata-se da função identitária do professor, mediar o saber elaborado, o qual deve ser apropriado pelos estudantes; os materiais didáticos serviriam de apoio necessário, mas não central.

Estes conteúdos e saberes culturais, no contexto da EAC, devem referir-se à compreensão de que os problemas socioambientais estão diretamente e estreitamente relacionados ao sistema capitalista e para que se compreenda a complexidade de inter-relações que constituem esta totalidade, os currículos das instituições de formação de professores devem ser reformados (JUNQUEIRA, 2014).

$\mathrm{Na}$ formação inicial de professores devem estar presentes procedimentos e conhecimentos que proporcionem a compreensão dialética, no sentido de totalidade, de que a realidade escolar não está descolada da realidade e das contradições da sociedade capitalista. À EAC, então, a formação de professores/educadores ambientais deve proporcionar "uma reflexão crítica sobre a realidade objetiva, consolidando uma proposta formativa que contribui para promover o desenvolvimento da consciência filosófica, demanda legítima e necessária ao processo educativo escolar." (MAIA; TEIXEIRA, 2015, p. 294). Assim, o processo formativo de professores deve buscar formar educadores sábios, no sentido filosófico e dotados de capacidade crítica e autonomia efetiva. Para tanto, deve-se partir do que

Saviani (2007) chamou de "senso comum educacional". Neste estudo, o autor propõe que os professores superem o senso comum educacional pela consciência filosófica, isto é, que eles partam da realidade empírica do "que-fazer" educativo e, através de reflexões sobre os processos em questão, atinjam a consciência filosófica. Podemos dizer, então, que o autor nos orienta a superar, pelo movimento de ação-reflexão-ação, a tendência de fazer do processo educativo uma ação que separa a prática da teoria na educação escolarizada das crianças, jovens e adultos (MAIA; TEIXEIRA, 2015, p. 294).

Este que-fazer educativo refere-se, em grande medida, à mediação didática. Esta foi foco de preocupação de Saviani, que se dedicou a didatizar o procedimento que o professor deve 
realizar para que transponha ao universo escolar a real relação entre a o real social (no caso da EAC o real socioambiental) e a compreensão deste mesmo real realizada pela ciência e demais saberes sistematizados ao longo da história da humanidade. Veremos a seguir.

\section{Mediação didática: os passos/momentos da Pedagogia Histórico-Crítica}

Mas como realizar um processo de mediação didática de saberes sócio-históricos desveladores das relações dialéticas acima descritas? Os saberes científicos, enquanto conhecimentos construídos dentro de uma matriz epistemológica não crítica, são os mais adequados? Ou isto depende de como o processo de mediação didática é realizado e de seus objetivos? Deve-se levar em conta que as categorias socioambientais são complexas, pois carregam consigo processos ecológicos complexos e modos de alteração destes processos carregados de interesses fundados em relações sociais também complexas, além de acarretar consequências socioambientais deletérias múltiplas e encadeadas. Complexidade aqui é compreendida como totalidade concreta dialeticamente articulada em totalidades parciais (KOSIK, 2011). Essa estrutura constitutiva do ser, a que Lukács (2010) designa como um complexo de complexos. Relembremos que

\footnotetext{
a assimilação da cultura, a compreensão da totalidade e a essência dos fenômenos - sejam eles naturais, sociais ou históricos - que exige uma ação intencional e sistematizada. Nesse sentido, é da educação escolar que se ocupa - prioritária, mas não exclusivamente - a pedagogia histórico-crítica [...]. Aqui estamos tratando de conteúdos tratados de forma crítica com o objetivo de apropriação dos elementos da cultura voltados para a transformação social. (LOUREIRO; TOZONI-REIS, 2016, p. 77).
}

É justamente da primaz relevância da apropriação da cultura que Saviani (2013), afirma que é nas sociedades modernas que a escola deve ter essa função específica de socialização do saber sistematizado pela cultura.

Os momentos propostos pela PHC apontam para uma problematização que parte da identificação de problemas a partir das práticas sociais. "O ponto de partida é a prática social" (SAVIANI, 2009). Segue-se a apropriação de instrumentos teóricos e práticos para o equacionamento dos problemas, a instrumentalização. Conclui-se com a incorporação dos instrumentos culturais (concebidos como familiares aos alunos) e transformando-os em elementos ativos na transformação socioambiental.

No ponto de partida da PHC temos o primeiro momento que é a prática social, que é tida como ponto de partida do trabalho pedagógico. Este primeiro momento é a primeira leitura da realidade. Consiste em ver a realidade e tomar consciência de como ela se coloca no seu todo em suas relações (SAVIANI, 2009). Neste momento, professor e alunos se impõem como agentes sociais distintos, representando diferentemente a prática social que lhes é comum (MARTINS, 2013).

A prática social inicial é a realidade concreta de professores e alunos derivada de uma realidade historicamente fundada. Esta construção do ser social é marcada por múltiplas determinações que auxiliaram a constituição da sociedade atual a partir do trabalho e da apropriação de conhecimentos sistematizados. Outras teorias pedagógicas também tratam de uma pratica 
social primeira, entretanto esta trazida por Saviani se caracteriza por ir para além de um momento didático; é uma prática social que possibilita uma compreensão do sujeito no mundo; nela, o eu e o nós se interpenetram e o sujeito se compreende na coletividade.

Do ponto de vista mais amplo, para a PHC o problema geral que está posto ao trabalho pedagógico é: como promover o desenvolvimento humano do sujeito por meio da apropriação do conhecimento científico? Desta forma, esse problema deve emergir de uma prática social como fenômeno histórico. De acordo com Martins (2013), o segundo momento aponta na direção das condições requeridas ao trabalho pedagógico, à prática social docente. Assim, cabem enquanto questões a serem problematizadas: o fracasso acerca da aprendizagem dos alunos, as carências infraestruturais, os baixos salários, os domínios teórico-técnicos oriundos da formação docente, a estrutura organizativa da escola, dentre outros. Segundo Pinheiro (2016, p. 131) "neste passo o professor deve tencionar a realidade escolar e social do aluno a fim de que professor e aluno identifiquem os principais problemas postos à prática educativa".

Segundo Martins (2013), o terceiro momento, denominado instrumentalização, diz respeito à apropriação dos instrumentos teóricos e práticos requeridos aos encaminhamentos dos problemas identificados. Trata-se do momento no qual se destaca, por um lado, o acervo de apropriações de que dispõe o professor para objetivar no ato de ensinar, isto é, dos objetivos, da seleção de conteúdos e procedimentos de ensino, dos recursos didáticos que lançará mão e, fundamentalmente, de uma perspectiva de análise da realidade social que articule o lógico/categorial e o histórico. Por outro, trata-se das apropriações a serem realizadas pelos alunos do acervo cultural indispensável à sua formação escolar, as quais lhes permitam superar a sincrese em direção a sintese.

De acordo com Saviani (2009), a catarse representa o ponto alto dos momentos anteriores. Nela ocorre a incorporação dos instrumentos culturais, transformados agora em elementos ativos de transformação social. Este é o momento de sistematização e de manifestação do conhecimento que foi apropriado na instrumentalização. Agora, o estudante expressa, de uma nova maneira, a sua visão acerca dos conteúdos/conhecimentos que estão imersos na prática social. Ele é capaz de entendê-los em um novo patamar, mais sintético, mais consistente e mais bem estruturado, do ponto de vista lógico e histórico. Neste momento a humanidade produzida pelo conjunto dos homens se efetiva em cada sujeito singular.

Por fim, o quinto passo/momento, que é um retorno a uma prática social agora mais elaborada através dos conhecimentos específicos que permitiram a síntese em questão. A concepção de realidade está mais impregnada de saberes científicos, na busca de nexos e significados do real. Nesta fase reconhece-se que professor e educando modificaram-se intelectual e qualitativamente em relação a suas concepções sobre o conteúdo que reconstruíram, passando de um nível de menor compreensão científica para um nível de maior cientificidade da explicação da realidade, dentro de uma vertente crítico-dialética. Neste ponto de chegada, tanto o professor, quanto o estudante, são novos sujeitos do ponto de vista epistemológico. O aluno não se encontra mais com um pensamento sincrético frente aos conhecimentos relacionados ao problema posto pela prática social no início do processo de ensino e o professor superou a sua síntese precária; agora, professor e estudante possuem um pensamento sintético, mas diferentes, pelo teor desta síntese (PINHEIRO, 2016).

Considerando esta didática como importante ao projeto político-pedagógico da EAC, resta-nos levantar a questão da dificuldade de mediar conhecimentos de diversas ciências (Artes e Filosofia também) (DUARTE, 2016; DUARTE et al., 2013) ao universo escolar e, considerando 
as especificidades econômicas e culturais dos educandos, mas sem perder seu caráter emancipatório e revolucionário, o que descaracterizaria o mote humanizante comum à PHC e à EAC.

\section{Considerações finais}

Sendo assim, por meio da mudança cultural e da mudança social, concentrando-se na crise socioambiental, para a EAC, a categoria "Natureza" aparece como privilegiada, mas com uma definição ampliada, considerando a histórica humana como seu agente moldador (LAYRARGUES, 2006). Frise-se aqui que o propósito de mudança cultural e de mudança social são claramente compartilhados por ambas as vertentes educacionais aqui analisadas. Outro aspecto relevante é a atenção dada por ambas as vertentes aos conteúdos científicos, sem jamais descaracterizar o papel do estudante e do educador-filósofo, portador de uma atitude intencional, não espontânea, pensador dos problemas da existência humana (SAVIANI, 1975). Como afirmado por Loureiro et al. (2009, p. 88) "A proposta central aqui diz respeito à garantia, pelo educador, desta apropriação através de uma atuação direta e intencional, que crie condições educativas de reflexão crítica destes conteúdos".

O sistema social, historicamente construído, deve ser concebido como dinâmico - o que significa que seus complexos sociais (dentre estes a Educação) mantém papel ativo em sua dinâmica, diferentemente do que concebe as chamadas teorias crítico-reprodutivistas, que conferem à educação apenas o papel de reprodução ou reforço da sociedade na qual esta se insere (SAVIANI, 2009).

Assumindo a natureza como pressuposto do ser humano e admitindo a contradição, o trabalho e a práxis como condições necessárias da existência do real histórico - a EAC vem construindo seu objeto de estudo e sua especificidade enquanto vertente educacional. Compreender a dialética materialista histórica marxista é o caminho adequado para que se conceba a matriz filosófica, ontológica e político-pedagógica que é comum entre a EAC e a PHC. Ou seja, a noção de realidade e de ser humano.

No que se refere à natureza da educação enquanto práxis humana relativa à natureza, a categoria trabalho possui o mesmo papel ontológico: é o trabalho que constitui o cerne que caracteriza a EAC e a PHC como atividades, como processos humanos e humanizantes.

A formação do sujeito, por meio da educação crítica, deve ocorrer mediante processos reflexivos que se pautam na discussão, compreensão e ação transformadora sobre as relações sociais de dominação. Conforma-se, desta forma, um objetivo político-transformador da educação crítica (TOZONI-REIS, 2007). Para que ocorra a emancipação, deve-se partir do conhecimento da realidade, considerando sua complexidade e processos de alienação e de expropriação.

Ao falar em pedagogia ambiental crítica, devemos associá-la a um objetivo de desvelar os processos econômicos e políticos da relação ser humano-natureza, além de integrá-la aos componentes epistemológico e pedagógico que compõem esta vertente ambiental da educação. A práxis pedagógica, em decorrência, enquanto um procedimento cotidiano de vinculação consciente do que é refletido, deve ser pensada concomitantemente com as ações e práticas humanas sobre a natureza, com a meta de superação da compreensão quotidiana, em busca da construção do saber sábio a ser mediado no ambiente escolar. (PINHEIRO, 2016; SAVIANI; DUARTE, 2012). 


\section{Referências}

BIRAL, R. B. A dialética na educação ambiental: elementos para pensar a prática docente. REMEA, Rio Grande, v. especial, p. 29-46, 2014. Disponível em: < https://www.seer.furg. br/remea/article/view/4429/2782>. Acesso em: 29 jan. 2018.

DUARTE, N. Os conteúdos escolares e a ressurreição dos mortos: contribuição à teoria histórico-crítica do currículo. Campinas: Autores Associados, 2016.

O debate contemporâneo das teorias pedagógicas. In: MARTINS, L. M.; DUARTE, N. (Org.). Formação de professores: limites contemporâneos e alternativas necessárias. São Paulo: Cultura Acadêmica, 2010. p. 33-49.

. Educação, teoria do cotidiano e a escola de Vigotski. Campinas: Autores Associados, 2007.

. Lukács e Saviani: a ontologia do ser social e a pedagogia histórico-crítica. In: SAVIANI, D.; DUARTE, N. (Org.). Pedagogia histórico-crítica e luta de classes na educação escolar. Campinas: Autores Associados, 2012. p. 1-17.

DUARTE, N. et. al. Marxismo e a questão dos conteúdos escolares. In: SEMINÁRIO NACIONAL DE ESTUDOS E PESQUISAS "HISTÓRIA, SOCIEDADE E EDUCAÇÃO NO BRASIL”, 9., 2013, João Pessoa. Anais eletrônicos... Disponível em: $<$ http://www.histedbr.fe.unicamp.br/acer_histedbr/seminario/seminario9/PDFs/6.17. pdf $>$. Acesso em: 29 jan. 2018.

GRAMSCI, A. Concepção dialética de história. Rio de Janeiro: Civilização Brasileira, 1996.

JUNQUEIRA, J. N. Por uma educação ambiental histórico-crítica na escola. 2014. 144 f. Tese (Doutorado em Educação para a Ciência) - Faculdade de Ciências, Universidade Estadual Paulista, Bauru, 2014.

KOSIK, K. Dialética do concreto. Rio de Janeiro: Paz e Terra, 2011.

KUENZER, A. Z. Exclusão includente e inclusão excludente: a nova forma de dualidade estrutural que objetiva as novas relações entre educação e trabalho. In: LOMBARDI, J. C.; SAVIANI, D.; SANFELICE, J. L. (Org.). Capitalismo, trabalho e educação. Campinas: Autores associados, 2005. p. 77-96.

LAYRARGUES, P. P. Muito além da natureza: educação ambiental e reprodução social. In: LOUREIRO, C. F. B.; LAYRARGUES, P. P.; CASTRO, R. C. (Org.). Pensamento complexo, dialética e educação ambiental. São Paulo: Cortez, 2006. p. 71-103.

LESSA, S.; TONET, I. Introdução à filosofia de Marx. São Paulo: Expressão Popular, 2011.

LOUREIRO, C. B. F. Educação ambiental e epistemologia crítica. REMEA, Rio Grande, v. 32, n. 2, p. 159-176, 2015. Disponível em: < https://www.seer.furg.br/remea/article/ view/5536/3443>. Acesso em: 29 jan. 2018. 
Peneluc, M. C.; Pinheiro, B. C. S.; Moradillo, E. F.

LOUREIRO, C. B. F. Materialismo histórico-dialético e a pesquisa em educação ambiental. Pesquisa em Educação Ambiental, São Carlos, v. 9, n. 1, p. 53-68, 2014.

LOUREIRO, C. F. B.; TOZONI-REIS, M. F. C. Teoria social crítica e pedagogia históricocrítica: contribuições à educação ambiental. REMEA, Rio Grande, número especial, p. 68-82, 2016. Disponível em: <https://www.seer.furg.br/remea/article/view/5960/368>. Acesso em: 29 jan. 2018.

LOUREIRO, C. F. B.; VIÉGAS, A. Princípios normativos da educação ambiental no Brasil: abordando os conceitos de totalidade e de práxis. Pesquisa em Educação Ambiental, São Carlos, v. 8, n. 1, p. 11-23, 2013.

LOUREIRO, C. B. F. et al. Contribuições da teoria marxista para a educação ambiental crítica. Cadernos Cedes, Campinas, v. 29, n. 77, p. 81-97, 2009. Disponível em: < https:// doi.org/10.1590/S0101-32622009000100006>. Acesso em: 29 jan. 2018.

LUKÁCS, G. Prolegômenos para uma ontologia do ser social: questões de princípios para uma ontologia hoje tornada possível. São Paulo: Boitempo, 2010.

MAIA, J. S. S. Problemáticas da educação ambiental no Brasil: elementos para reflexão.

REMEA: revista eletrônica do mestrado em educação ambiental, Rio Grande, v. 32, n. 2, p. 283-298, 2015. Disponível em: < https://www.seer.furg.br/remea/article/view/5544/3452>. Acesso em: 29 jan. 2018.

MAIA, J. S. S.; TEIXEIRA, L. A. Formação de professores e educação ambiental na escola pública: contribuições da pedagogia histórico-crítica. Revista HISTEDBR On-line, Campinas, v. 15, n. 63, p. 293-305, 2015.

MARX, K. Contribuição à crítica da economia política. São Paulo: Expressão Popular, 2007.

Manuscritos econômicos-filosóficos. São Paulo: Boitempo, 2008.

MARSIGLIA, A. C. G.; MARTINS, L. M. Contribuições da pedagogia histórico-crítica para a formação de professores. Germinal, Salvador, v. 5, n. 2, p. 130-143, 2013. Disponível em: $<$ https://portalseer.ufba.br/index.php/revistagerminal/article/view/9702/7090>. Acesso em: 29 jan. 2018.

MARTINS, L. M. O desenvolvimento do psiquismo e a educação escolar: contribuições à luz da psicologia histórico-cultural e da pedagogia histórico-crítica. Campinas: Autores Associados, 2013.

. O legado so século XX para a formação de professores. In: MARTINS, L. M.; DUARTE, N. (Org.). Formação de professores: limites contemporâneos e alternativas necessárias. São Paulo: Cultura Acadêmica, 2010. p. 13-31. Disponível em: <http://books. scielo.org/id/ysnm8/pdf/martins-9788579831034-02.pdf>. Acesso em: 29 jan. 2018.

NETTO, J. P.; BRAZ, M. Economia política: uma introdução crítica. São Paulo: Cortez, 2009. v. 1. 
PINHEIRO, B. C. S. Pedagogia histórico-crítica na formação de professores de ciências. Curitiba: Apris, 2016.

SALA, M. Alienação e emancipação na transmissão do conhecimento escolar: um esboço preliminar. In: MARTINS, L. M.; DUARTE, N. (Org.). Formação de professores: limites contemporâneos e alternativas necessárias. São Paulo: Cultura Acadêmica, 2010. p. 83-97. Disponível em: < http://books.scielo.org/id/ysnm8/pdf/martins-9788579831034-06.pdf>. Acesso em: 29 jan. 2018.

SAVIANI, D. Escola e democracia. Campinas: Autores Associados, 2009.

. A filosofia na formação do educador. Revista D/doto, São Paulo, n. 1, 1975.

Disponível em: <http://portalgens.com.br/portal/images/stories/pdf/A_filosofia_na_ formao_do_educador.pdf>. Acesso em: 29 jan. 2018.

Pedagogia histórico-crítica: primeiras aproximações. Campinas: Autores

Associados, 2013.

Sobre a natureza e especificidade da educação. Germinal, Salvador, v. 7, n. 1, p.

286-293, 2015. Disponível em: <https://doi.org/10.9771/gmed.v711.13575>. Acesso em: 29 jan. 2018.

SAVIANI, D.; DUARTE, N. A formação humana na perspectiva histórico-ontológica. In: . (Org.). Pedagogia histórico-crítica e luta de classes na educação escolar.

Campinas: Autores Associados, 2012. p. 13-35.

TOZONI-REIS, M. F. C. Contribuições para uma pedagogia crítica na educação ambiental: reflexões teóricas. In: LOUREIRO, C. F. B. (Org.). A questão ambiental no pensamento crítico: natureza, trabalho e educação. Rio de Janeiro: Quartet, 2007. p. 177-221.

TOZONI-REIS, M. F. C.; CAMPOS, L. L. Educação ambiental escolar, formação humana e formação de professores: articulações necessárias. Educar em Revista, Curitiba, n. 3, p. 145-162, 2014. Edição especial.

TOZONI-REIS, M. F. C. et. al. Conteúdos curriculares da educação ambiental na escola: contribuições da pedagogia histórico-crítica. In: ENCONTRO DE PESQUISA EM EDUCAÇÃO AMBIENTAL, 7., 2013, Rio Claro. Anais... Disponível em: <http://www. epea.tmp.br/epea2013_anais/pdfs/plenary/0190-1.pdf>. Acesso em: 29 jan. 2018.

TREIN, E. S. Educação ambiental crítica: crítica de que? Revista Contemporânea de Educação, Rio de Janeiro, v. 7, n. 14, p. 304-318, 2012.

Artigo recebido em 26/07/2016. Aceito em 19/08/2017.

Endereço para contato: Campus Ondina, Instituto de Química, Rua Barão de Jeremoabo, s/n, CEP 40170-290, Salvador, BA, Brasil. 